\title{
A Mulher na Diplomacia
}

\author{
Prelecção de encerramento dos \\ cursos juridicos na Faculdade \\ de Direito de São Paulo, em \\ 21 de Novembro de 1931
}

O thema que me proponho desenvolver, nesta prelecção de encerramento dos cursos juridicos, é o da conveniencia de serem aproveitadas as mulheres nos cargos diplomaticos, assumpto pouco estudado pelos internacionalistas, que o ventilam superficialmente.

Comquanto a escolha do agente diplomatico dependa exclusivamente do estado que o consttiue, raramente têm sido as mulheres empregadas na diplomacia, não sendo comtudo o sexo, na opinião abalisada de HefFTer, um obstaculo á carreira diplomatica. (1)

Da mesma opinião é Calvo que diz que o sexo não é impedimento para a escolha do agente diplomatico. (2)

(1) Heffter, Le Droit International de l'Europe, trad. Bergson, $1866, \S 209$.

(2) Calvo, Le Droit International Théorique et Pratique, t. I, p. 480 . 
Observa Oppenheim, o insigne e saudoso Mestre da Universidade de Cambridge que, apesar de não ter conhecimento de mulheres diplomatas nos ultimos dois seculos, não põe duvida em que o Direito das Gentes não prohibe o emprego dellas como representantes acreditadas pelo governo de um estado, perante o governo de outro, para zelar os seus direitos e interesses. (3)

\section{OPINIÃO DE OUTROS INTERNACIONALISTAS}

Bynkershoeck, cuja opinião estudarei mais de espaço, sustenta que podendo uma mulher subir ao throno, nada impede que ella represente o estado no exterior, occupando um cargo diplomatico. (4)

E identico é o pensar de Carnazza Amari (5) e do preclaro Phillimore (6) que affirmam, de módo categorico, não poder um estado rasoavelmente recusar-se a receber um agente diplomatico devido ao sexo.

\section{RESTRICÇÕES}

A essas opiniões oppõem comtudo os jurisconsultos certas restriç̧ões.

O proprio Oppenheim diz que nas actuaes condições muitos estados talvez recusem acceital-as.

Gama Lobo, (7) após enumerar casos de mulheres diplomatas, diz que os nossos habitos e a educação que damos

(3) Oppenheim, International Law, V. I. p. 549 § 370.

(4) Bynmershoeck, Quest Juris Publ., Lib. II.

(5) Carnazza Amari, Trat. de Dir. Int. trad. de Montanari, Revest, 1882, v. II, p. 158.

(6) Phillimore, Int. Law, II p. 179: "A State cannot reasonably refuse to receave an Ambassador on the grounds of sex".

(7) Gama Lobo, V. I, p. 138. 
ás mulheres, parecem reprovar a admissão destas pessôas para o exercicio das funcções diplomaticas.

Essa objecção é fraquissima pois argumentava GaMA Lово com a educação das mulheres portuguezas de seu tempo, beatas, cheias de preconceitos obsoletos, escravizadas ao homem, esquecendo-se comtudo de que ha paizes em que as mulheres são educadas e livres e outros em que são mais instruidas do que os proprios homens : - haja vista os Estados Unidos.

Leiam-se, para comprovar o seu assérto, as paginas encantadoras do eminente diplomata, o saudoso OliverRa Lima (8), sobre a influencia da mulher americana na sociedade. Partindo da convicção profunda da identidade de aptidão mental dos dois sexos, é que os americanos entenderam proporcionar no seu paiz, ás mulheres, as mesmas facilidades de educação que aos homens.

Lembrarei os collegios onde as mulheres têm o ensino superior, ou alta sciencia: Wellesley, Vassar, Bryn Mawr. Nelles, ao lado dos laboratorios mais perfeitos e da vida escolar sabiamente regulada, têm o campo livre para o pleno desenvolvimento da personalidade, com o aspecto typico da educação americana, tão bem apprehendida por Oliveira Lima, de preparação para a vida pratica, em que se entrelaçam os estudos serissimos, os prazeres da vida social e as obrigações mais penosas do serviço domestico, o que caracteriza o ensino universitario naquella grande Republica.

Sinto que o escasso tempo de que disponho e o temor de fugir ao thema que me impuz desenvolver, me impidam de fazer um estudo aprofundado da influencia da mulher na civilização americana. Brilhando em todos os ramos da actividade social, o sexo feminino é representado por nomes da grandeza de Helen Hunt Jackson, a defensora dos indios, Beecher Stowe, a autora do célebre romance $A$ Cabana do

(8) Oliveira Lima, Nos Estados Unidos. 
Pae Thomaz, tendo o lar americano uma feição caracteristica, como tão agudamente salienta o brilhante escritor Plinio Balmaceda (9), na sua maravilhosa obra sobre a America do Norte, emquanto o marido se limita a proporcionar o bem estar material da familia, a mulher se incumbe de proporcionar o bem estar espiritual.

A esse altissimo espirito, que honra a nossa intellectualidade, me repórto, certo de que os que percorreram as paginas profundas de seu empolgante trabalho, lá encontrarão a prova das minhas affirmações.

Falla-se muito em falta de educação da mulher, em deficiente instrucção do povo, em crise de estadistas. Mas, pergunto eu, que se fez entre nós para corrigir esses males reaes? Nada!

Sabeis perfeitamente a campanha que tenho feito em pról da educação do nosso povo. Precisamos reformar os nossos archáicos methodos de ensino, incompativeis com a civilisação contemporanea. Emquanto a revolução redemptora, não mudar a nossa mentalidade, não dér ao povo, recorrendo á taxa universitaria, ensino gratuito e obrigatorio, não terá realizado seus grandes ideaes.

Só teremos technicos, estadistas, homens competentes e capazes de transformar este grande paiz, quando o nosso ensino orientar-se de accôrdo com os principios scientificos. Como salientei no meu trabalho - O Problema Universitario, os nossos pedagogos ignoram os mais rudimentares principios da Psychotechnia, e nem siquer pensaram ainda na necessidade do exame de vocação profissional entre nós, já reconhecida em 1919, pela Constituição Allemã, no seu artigo 146.

Façamos, pois, de nossas escolas superiores, viveiros de technicos, aproveitando as capacidades, erguendo o nivel moral e intellectual da mocidade, em vez de tornal-a servil e abastardada, descrente e sceptica, pela obrigação de obter

(9) Plinio Balmaceda Cardoso, Estados Unidos da America do Norte, São Paulo, 1930. 
empregos e triumphar, não pelo esforço e pela competencia, mas sim pela bajulação e pelo nepotismo.

\section{CONTRA AS DIPLOMATAS}

Os que acham impossivel o aproveitamento da mulher na diplomacia baseam-se geralmente, não na sua incapacidade, mas sim nas intrigas e paixões que poderiam agitarse em torno dellas.

E' essa a argumentação de D'Esperson e de Pradier FODERÉ. (10)

Poderiamos oppor, que é ao Estado a quem compete a escolha de seu representante que cabe examinar sua aptidão, para levar a cabo, vantajosamente, uma missão diplomatica, e, si acha que é uma mulher que está em condições, nada impede que a designe para ella. E é o mesmo Pradier que nảo nega que as mulheres tenham influencia na diplomacia, pois, baseado em Heffter (11), cita o caso de Mlle. de Keroual que, pelos seus dotes, conseguiu para a França, na côrte de Carlos II, da Inglaterra, mais do que um congresso de paz (12). E não é tudo, é o proprio Pradier que se incumbirá de dissipár os seus falsos temores, affirmando que: "... as mulheres excellem em abrandar as naturezas duras ou irritadas e approximar os espiritos que um pouco de colera e resentimento afastou uns dos outros". (13)

E HEFFTER, enumerando os maiores caracteres diplomáticos do mundo, não se refere a Isabel da InglaterRa e CATHARINA DA RUSSIA?

(10) N. ${ }^{\circ} 38$, p. 28, nota 1.

(11) N. ${ }^{\circ} 232$, p. 437.

(12) "Mll. de Keroual à la taille, à la bouche fines, aux beaux yeaux, a obtenu pour la France, à la cour de Charles II d'Angleterre, bien plus qu'un congrés de paix" (Heffter $n .^{\circ} 232$ ).

(13) “ .les femmes sont èminentement propres à fléchir les natures incisives on trop irrités, et à rapprocher des esprits qu'un peu de colère et de ressentiment éloigne les uns des autres" (V. I, p. 345). 


\section{A OPINIÃO DE BYNKERSHOECK}

Foi o excelso Bynkershoeck, quem melhor discutiu a thése que nos interessa, debatendo brilhantemente a complexa questão da legalidade e conveniencia do aproveitamento das mulheres para embaixadoras.

Diz Bynkershoeck que Zouch, no seu Jus Feciale (14), dá a opinião contraria ás embaixadoras de Kirchner e favoravel de PASchaL, com os respectivos argumentos.

Critica o grande jurista hollandez acerbamente a Zouch, o segundo fundador do Direito das Gentes (15), a quem, com a costumada virulencia, declara um indeciso em materia doutrinária, Realmente Zouch não dá no caso, como de costume, diria Bynkershoeck, uma regra explicita e os argumentos tirados por elle do Direito Romano são de pequeno valor, pois, por não poder advogar, não se ségue que esteja a mulher impedida de chefiar embaixadas e occupar outros cargos publicos e civis.

E resolve BynkERSHOEck categoricamente o caso raciocinando que, si a mulher é admittida a reinar, nada admira que possa ser embaixadora de uma rainha.

Quanto á capacidade para occupar o cargo, salienta o clarissimo jurista hollandez, a mulher não é inferior ao homem, pois a intelligencia e a diligencia são eguaes em ambos, e-mesmo é a mulher frequentemente mais capaz que o homem. (16)

(14) Juris et Judicii fecialis, sive Juris inter Gentes, e Questionum de odem Explicatio, qua, quœ ad Pacem e Bellum inter diversos Principes aut Populos spectant, ex Proecipuis historico Jure peritis exhibentur. Ed. por Holland, Scott's Classics of Int. Law, trad. ingleza de Brierly (1911).

(15) "Second founder of the Law of Nations". (OPPENHEIM, Int. Law, I, p. 103).

(16 e 17) "Audio, at quœri, an magis decorum sit, feminas Regnum obtinere? Si it patieris, ut patiuntur multae gentes, cur non etiam pateris ad Reginam feminam it legationem mitti?" 
Quanto ao juizo, não é privilegio masculino, accrescenta elle, citando Plutarcho, que narra o facto de tomarem as mulheres celtas parte nos conselhos de guerra e de paz, o que tambem acontecia entre os germanos, segundo $\mathrm{T}_{\mathrm{A}-}$ cito.

Conclúe Bynkershoeck pela affirmativa, energica e definitiva, de que a mulher, que póde occupar um throno, póde ser representante de uma rainha. (16-17)

\section{HISTóRICO}

Várias foram as mulheres que brilharam na diplomacia, em todas as épocas. Já nos primeiros tempos da Republica Romana, discutia-se largamente a questão de saber, se a mulher póde ser embaixadora. Tratava-se de deputar Veturix e Volumnia (18) junto a Cariolano e temia o povo juridico por excellencia violar o Direito das Gentes. Emfim foram ellas enviadas e. . salvaram Roma!

No reinado de Henrique IV, uma mulher foi enviada em embaixada a Constantinopla, segundo conta MathIEU. (19)

\section{A CONDESSA DE HESSELLES DE BRÉGI}

substituiu seu marido na Polonia e na Suecia, correspondendo-se como embaixadora, com Luiz XIV e toda a Europa. (20)

(18) Vide: - Trтo Lrvıo, 1. 2; Dionysio Halicarnasso; e, "Gran Diccionario Historico" de Joseph de Mariavel y Casadavante (1753). verbs. Veturia.

(19) Merlin, Répertoire universal de Jurisprudence, Verbs. Ministre Public, sect. III, n. ${ }^{\circ} 3$.

(20) "La Contesse de Hesselles de Brégi fut Ambassadrice, en Pologne et entretin, en cette qualité une correspondence avec toute l'Europe" (Carnazza Amari). 
Além da célebre Marechala de Guébriant, da qual falaremos em seguida, numerosas são as mulheres que, comquanto não occupassem cargos effectivos, mostraram aptidões excepcionaes para a diplomacia.

Apontarei Lady Mary Wortley Montague, filha do Duque DE Kingston, considerada a Mme. de Sévigné ingleza, que tratou de vários negocios de interesse da Inglaterra junto á Porta Ottomana.

\section{PAIX DES DAMES}

Em 1529, Luiza de Savoia, mãe de Francisco I e Margarida d'Austria, tia de Carlos V, concluiram em Cambrai, o tratado denominado - paz das mulheres (Paix des Dames), posto que, na opinião de Pradier Foderé (21), não agissem na qualidade de embaixadoras nomeadas.

\section{A DUQUEZA D’ORLEANS}

Henriqueta, Duqueza d'Orleans (Madame), irmã de Carlos II da Inglaterra, tão bem retratada por MME. DE LAFAYETTE (22), foi uma diplomata notavel. Negociou em 1670, a alliança entre a França e a Inglaterra, desligada de sua alliança com a Hollanda, concluindo o tratado de Douvres. O historico deste tratado é interessantissimo. Carlos II, procurando dinheiro, depois de vender Dunkedque (a conquista de Cromwell) a Luiz XIV (1670), pelo tratado de Douvres, vende-lhe tambem sua alliança com a Hollanda.

Madame na sua missão foi muito auxiliada pela célebre Mlle. de Keroual (Louise Renée du Pen An Couet de Ke-

(21) Pratder Foderé, Cours de Droit Diplomatique (t. I, p. 344).

(22) Histoire de Mme. Henriette d'Angleterre, par Mme. de Lafayette, La Haye (1720). Esta obra foi reimpressa varias vezes. Além da edição original. (Amsterdam, 1720, in $12 .^{\circ}$ ), existem Asse (Paris, 1890) e Anatole France (Charavay, 1882). 
roual), Duqueza de Portsmouth, que mais tarde se revelaria uma politica admiravel, capaz de dar lições ao proprio Machiavel.

\section{MME. DE GUÉBRIANT}

Renée du Bec, Marechala de Guébriant, foi incumbida, em 1645, por Luiz XIV, de conduzir, como embaixadora extraordinaria, a Vladisláu IV, a Princeza Maria de Gonzaga, com quem este rei da Polonia, casára por procuração. Em Varsovia, o rei foi grosseirissimo com a Princeza, e chegou a querer devolvel-a. Graças, porém, á habilidade de Guébriant, a rainha foi reconhecida, e a esta foram tributadas as mesmas honras que a Claddia de Medicis, Archiduqueza d'Inspruck, quando levára a Varsovia a primeira esposa de LAdisLaU IV. Terminando assim, brilhantemente, a espinhosa missão na Polonia, teria ainda em 1682, opportunidade de servir a patria, demonstrando, mais uma vez, a sua extraordinaria perspicacia, decisão e machiavelismo, salvando para a França, por um habil estratagema, a fortaleza de Brisach.

\section{QUALIDADES DO DIPLOMATA}

Verificámos, pois, que ha exemplo de mulheres que foram brilhantes diplomatas: - praticamente, a diplomacia feminina deu bons resultados. Não nos referiremos ao uso da mulher na espionagem, que seria um desvio da róta que nos traçámos, pois todos reconhecem que, nesta especialidade, são inexcediveis. (23)

Vejamos agora as qualidades de um bom diplomata.

A diplomacia, nada mais é, do que a applicação da intelligencia e do tacto ás relações entre os Estados e a arte

(23) "Aujourd'hui on envoye quelque fois des émissaires en jupon, chargés de missions secrètes. C'est une mode pratiquée par certaines Cours avec beaucoup de succès". (HefFrer, cit. § 209). Vide: Les femmes et l'Éspionage, RoBerto Boucard. 
de conciliar os interesses do paiz com os do Estado, junto ao qual, o agente está acreditado e com os da sociedade cosmopolita, cultivando um espirito, uma mentalidade internacional. Ora, para realizar esta missão, parece-me, nada falta á mulher: - intelligencia e tacto, eis as qualidades essenciaes ao diplomata.

Tão intelligente como o homem, a mulher tem, sobre elle, indiscutivelmente a vantagem do tacto, do savoir-faire, do refinamento de maneiras, sendo portanto, mais capaz do que elle, de representar, com habilidade, os interesses do paiz no extrangeiro.

CzILassi enumera as qualidades do diplomata e as analysa, manifestando-se contrario ás mulheres, na diplomacia.

$E^{\prime}$ a opinião de um reaccionario. Qualidades physicas, fortuna, familia, mérito, honestidade, religiosidade, dignidade, independencia, prudencia, dom de observação, delicadeza, pontualidade, laboriosidade: - em qual dellas é o homem superior á mulher?

\section{A SUPERIORIDADE FEMININA PARA A DIPLOMACIA}

Em um ponto, a mulher é superior ao homem, no tacto, na habilidade, na astúcia, no que poderiamos chamar - Machiavellismo, e no seu horror á violencia, á brutalidade, no amor profundo á paz: - qualidades fundamentaes para a diplomacia.

Fallo Machiavellismo na accepção exacta do que foi dito, pensado, ensinado por Machiavel.

Esse altissimo espirito, o grande e incomparavel Mestre da Politica, tem sido deturpado, atravez dos séculos.

Foi considerado pelos calvinistas, um conselheiro de violencias catholicas, um jesuita; pelos jesuitas, um atheu.

E' para uns, um simples burocrata, para outros, um bandido, ou o proprio demonio! (24)

(24) Gaspar Amico, Vita de Nicolo Machiavelli. 
Houve tambem, em compensação, quem o considerasse um santo!

- Sancte Machiavelli, ora pro nobis.

- San Machiavello, mi raccommando a te!

A expressão Machiavellismo significou anglicanismo, calvinismo, atheismo, incredulidade, tyrania, antipapismo, republicanismo, displomacia secreta, astucia, tortuosidade, hypocrisia; e é vulgar fallar-se em machiavellismo, politico, amoroso, juridico, feminino, etc.

Para mim, machiavellismo, é o que é ensinado por MAchiavel, no Principe, nos seus Discorsi, nas paginas immortaes que legou á posteridade, onde vasou, no seu estylo cortante, a rica e penosa experiencia dum profundo conhecedor do coração humano.

Machiavel não inventou o mal, a sua doutrina, basêase na observação dos factos: não aconselha, constáta. Espirito argúto, vê, clara e profundamente, o que se passa na realidade e tira as conclusões, exactas precisas. $O$ seu realismo é indifferente ao bem e ao mal, á verdade e á mentira: não é um moralista, é um politico.

A maldade do homem é velha como a humanidade e, no Genesis, disse o Senhor: - "Não amaldiçoarei mais a terra por causa dos homens: porque o sentido, e o pensamento do coração do homem, são inclinados para o mal, desde a sua mocidade..." (VIII-21).

A mulher tem o espirito de observação muito desenvolvido, o tacto, o tino, a habilidade, a astucia, e, neste sentido é machiavellica, conhecedora do coração humano e de suas maldades, sabendo, pois, defender-se das intringas, artimanhas e traições, communs na diplomacia, sem recorrer á força bruta, aos meios violentos e belluinos.

Na diplomacia, como em tudo, devemos tomar os homens como são na realidade, e não como deveriam ser ou desejariamos que fossem. 
Si o sexo masculino deu Cesar Borgia, "bellissimo ingano", Luiz XI a Raposa, Richelieu, Frederico II, Talleyrand c Bismarck; o feminino produziu Catharina de Medicis, a mais habil politica de todos os tempos. Emprensada entre principes que se diziam herdeiros de Carlos Magno e os facciosos de uma linha cadete; obrigada a combater a heresia, prestes a devorar a Monarquia, sem amigos, vendo a traição dos chefes catholicos e a republica, no partido calvinista, venceu, usando de uma arma unica, a mais certa e a mais perigosa: a astucia! Só os que leram o portentoso ensaio do cyclópico Balzac sobre Catharina de Medicis, poderão avaliar o genio dessa mulher sagacissima, e medir a verdade dos conceitos que acabo de emittir.

\section{OUTRAS MULHERES ILLUSTRES}

Posto que não fossem diplomatas profissionaes, ninguem, de bôa fé, negará o senso politico, as qualidades superiores que formam os verdadeiros estadistas e o genio diplomatico a Isabel d'Inglaterra, uma das figuras mais notaveis da historia da humanidade, Maria Thereza d'Austria; e, modernamente, á rainha Victoria ou a Imperatriz Zita. (25)

Si me sobrasse o tempo, referir-me-ia aos salóes politicos, cuja influencia é reconhecida pelos mestres.

Lembrarei os de Mme. Roland, Mme. Tallien, Mme. de Stael; e finalmente, os da célebre Princeza de Liéven e o da Baroneza de Krudener, (26) a mystica genial que, por intermédio de Alexandre da Russia, inspirou o famoso tratado da Santa Alliança.

E nada admira que a mulher brilhe na Diplomacia, ella que triumpha esplendidamente, em todos os ramos da acti-

(25) Revue des Deux Mondes (1.er Novembro, 1930).

(26) С̆. Eynard. Vie de Mme. de Krüdner; Saint Beuve, Portraits. 
vidade humana, como salienta Colette Yver, nos seus encantadores artigos, publicados na Revue des Deux Mondes (1929)

\section{MME. KOLLONTAI}

Bem inspirada a Russia Sovietica quando, rompendo com a rotina, zombando dos preconceitos estupidos, aproveitou as mulheres na diplomacia!

A terra das heroinas, abnegadas martyres da liberdade, de Vera Zasulich, de Vera Figner, de Brechowskaia, a avó da revolução e de Maria Spiridonova, livre das garras do tsarismo não podia deixar de, na sua nova róta, recorrer á mulher para collaborar com o homem, na reconstrucção social. E assim surgiram as diplomatas russas, dentre as quaes, se destaca a figura sympathica e fulgurante de $M m e$. Kollontai.

Iriamos longe, se traçassemos o perfil desta representante sovietica. Commissaria do Povo, reformista ousada, Ministra em Oslo, na Dinamarca, depois no Mexico, e finalmente em Londres, em toda a parte brilhou, honrando a intellectualidade russa.

\section{A MULHER E A PAZ}

A guerra ameaça o mundo, e a guerra futura será o cemiterio da civilização. (27) E' necessario que o povo saiba a ameaça que pesa sobre elle. Transformaram-se modernamente os processos bellicos e a lucta entre as nações, que era até pouco feita entre forças armadas, será de hoje em diante, dirigida contra os não combatentes, contra as populações inermes. (28)

(27) "Next War will be the cemetery of civilization" (Hoover).

(28) Henri Le Wita, Autour de la Guerre Chimique - Coment eviter ce fléau. 
Ninguem poderá escapar aos effeitos da guerra moderna. Demonstrei no curso de Direito Internacional, que não ha defesa contra a guerra chimica, pois esta consistirá unicamente, no contra ataque em territorio inimigo: - é a corrida para o massacre!

E' necessario acabar com a guerra, pol-a fóra da lei e isso só será possivel pela educação e esclarecimento das massas, pelo desenvolvimento de uma opinião publica mundial contra a guerra, pela formação do espirito internacional, pela triplice alliança dos intellectuaes honestos, das mulheres e da mocidade.

Ha como ensinei aos meus alumnos, poderosos interesses economicos, trabalhando a favor da guerra -- o trust internacional armamentista, denunciado por Light (29), Alen (30), Endres (31), Otтo Lehmann (32), e pela Conferencia de Francfort sobre o Meno.

Hoje, o mundo está senhoreado pelos fabricantes de armamentos, organizações poderosas, dominando a politica, a imprensa e a diplomacia.

Não mais haverá guerra, quando deixar de ser um negócio. Acabou-se com o cannibalismo, com a escravidão, com a tortúra: porque não acabaremos com a guerra?

$\mathrm{E}$ quem mais tem trabalhado pela paz?

\section{A mulher!}

Basta que vos lembre a Conferencia de Francfort sobre o Meno, (33) organizada pela Liga Internacional das

(29) BeRThÉlemy de Lighat, "Contre la Guerte Nouvelle".

(30) William C. Allen, War?

(31) Karl Endres, La Guerre des Gaz.

(32) Otтo LehmanN, La internacional Sangrienta de los Armamentos.

(33) Les Méthodes Modernes de Guerre et la protection des populations Civiles. (Paris, Marcel Riviére, 1929). 
Mulheres para a Paz e a liberdade, realizada em 1929, onde compareceram os maiores cerebros do mundo, votando uma nesolução contra a guerra, acontecimento dos mais notaveis da historia do pacifismo.

Não! Não podemos permanecer na estagnação e na rotina! Acabemos com a guerra, incompativel com a civilização.

Cooperem todos os homens, unam-se na lucta commum contra a natureza e as mizerias humanas, em vez de se destruirem, a serviço de interesses inconfessaveis que denunciámos.

E seja a mulher livre, egual ao homem, em direitos e deveres, a nossa companheira na lucta contra a guerra e contra a exploração do homem pelo homem, para que possamos realizar as palavras propheticas de Isaias: . . "Não levantará a espada uma nação, contra outra nação; nem dahi por diante se adéstrarão mais para a guerra." (34)

\section{BRAZ DE SOUSA ARRUDA \\ Professor cathedratico de Direito \\ Internacional Publico}

(34) Krehbiel, Nationalism, War and Society.

(34) IsAIAS X - 4. 